Discussion Paper No. 08-064

Knowledge Production in Nanomaterials:

An Application of Spatial Filtering to Regional Systems of Innovation

Christoph Grimpe and Roberto Patuelli

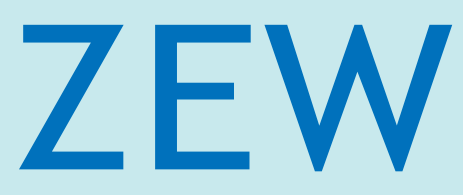

Zentrum für Europäische Wirtschaftsforschung $\mathrm{GmbH}$

Centre for European

Economic Research 
Discussion Paper No. 08-064

\section{Knowledge Production in Nanomaterials: An Application of Spatial Filtering to Regional Systems of Innovation}

Christoph Grimpe and Roberto Patuelli

Download this ZEW Discussion Paper from our ftp server:

ftp://ftp.zew.de/pub/zew-docs/dp/dp08064.pdf

Die Discussion Papers dienen einer möglichst schnellen Verbreitung von neueren Forschungsarbeiten des ZEW. Die Beiträge liegen in alleiniger Verantwortung der Autoren und stellen nicht notwendigerweise die Meinung des ZEW dar.

Discussion Papers are intended to make results of ZEW research promptly available to other economists in order to encourage discussion and suggestions for revisions. The authors are solely responsible for the contents which do not necessarily represent the opinion of the ZEW. 


\section{Non-technical summary}

Nanotechnology has been identified as one of the key technologies for the 21st Century. The application of nanotechnology is expected to result in new functionalities and properties for improving products or developing new products and applications. Nanotechnology is therefore believed to contribute substantially to innovativeness, economic growth and employment. Although the nanometre by definition corresponds to one millionth millimetre $\left(10^{-9} \mathrm{~m}\right)$ there is, however, no common understanding about what nanotechnology actually comprises. A reason for this might be the wide array of potential applications, e.g. in biotechnology, optics, chemistry or material sciences. Nanotechnology is hence seen as exhibiting certain characteristics of a 'General Purpose Technology (GPT)' like the information and communication technology. Due to this heterogeneity in applications this paper focuses on the intersection of nanotechnology and material sciences, an area where most of today's applications of nanotechnology have been achieved, e.g. in the 'lotus effect' of surfaces. The corresponding term 'nanomaterials' refers to functional structures sized less than 100 nanometres. Such structures give the material specific properties, allowing them to be used in new ways, to bring about new effects in larger structures of which they are part.

Given the perspective of many radically new applications, which could form the basis of innovative products, it seems all the more important for regions to put their own innovation systems in place, to ensure that they offer a suitable location for such work and are thus able to benefit from the growth that is expected to result from nanomaterial applications. Many regions have already done so by establishing 'science parks' and 'nanoclusters'. As nanomaterials are still in their infancy, both public research institutes and private businesses could play a vital role in the process. This paper investigates what conditions and configurations allow a regional innovation system to be competitive in a cutting-edge technology like nanomaterials. We analyse European Patent Office data at the German district level (NUTS-3) on applications for nanomaterial patents, in order to chart the effects of localised research and development (R\&D) in the public and private sector. We estimate two negative binomial models in a knowledge production function framework and include a spatial filtering approach to adjust for spatial effects. Our results indicate that there is a significant positive effect of both public and private R\&D on the production of nanomaterial patents. Moreover, we find a positive interaction between them which hints at the importance of their co-location for realising the full potential of an emerging technology like nanomaterials. 


\section{Das Wichtigste in Kürze}

Nanotechnologie wird als eine der Schlüsseltechnologien für das 21. Jahrhundert gesehen. So soll die Anwendung von Nanotechnologie dazu führen, dass existierende Produkte mit neuen Funktionalitäten und Eigenschaften ausgestattet oder sogar radikal neue Produkte auf den Markt eingeführt werden können. Der Anwendung von Nanotechnologie wird daher ein erheblicher Beitrag zur Innovationsfähigkeit, Wachstum und Beschäftigung zugesprochen. Obwohl ein Nanometer dem millionsten Teil eines Millimeters $\left(10^{-9} \mathrm{~m}\right)$ entspricht, fehlt jedoch bislang ein einheitliches Verständnis dafür, was Nanotechnologie tatsächlich ausmacht. Ein Grund dafür ist die Breite möglicher Anwendungen, z.B. in der Biotechnologie, Optik, Chemie oder den Materialwissenschaften. Nanotechnologie kann deshalb als Querschnittstechnologie wie auch die Informationstechnologie bezeichnet werden. Aufgrund der erheblichen Heterogenität nanotechnologischer Forschung bezieht sich daher dieser Beitrag auf die Schnittmenge von Nanotechnologie mit den Materialwissenschaften, ein Gebiet auf dem die bislang weitaus meisten Anwendungen von Nanotechnologie erreicht worden sind, beispielsweise in Form des „Lotus-Effekts“ bei Oberflächen. Die Bezeichnung Nanomaterialien bezieht sich daher auf funktionale Strukturen in der Größenordnung von weniger als 100 Nanometern. Solche Strukturen führen zu bestimmten Eigenschaften, die radikal neue Anwendungen in Produkten und Prozessen ermöglichen.

In diesem Sinne erscheint es daher von erheblicher Bedeutung, dass Regionen ihre Innovationssysteme auf solche Zukunftstechnologien ausrichten, um von den Innovationsund Wachstumspotenzialen zu profitieren. Viele Regionen haben dies bereits in Form von Wissenschaftsparks oder „Nano-Clustern“ getan. Da sich Nanomaterialien jedoch noch in einer sehr frühen Phase des Produktlebenszyklusses befinden, kommt der Interaktion zwischen öffentlicher und privatwirtschaftlicher Forschung und Entwicklung eine erhebliche Bedeutung zu. Dieser Beitrag untersucht daher, unter welchen Bedingungen ein regionales Innovationssystem wettbewerbsfähig in einer Zukunftstechnologie wie Nanomaterialien werden kann. Wir nutzen Patentdaten von Europäischen Patentamt auf der Kreisebene für Deutschland (NUTS-3) für die Anmeldung von Nanomaterialpatenten, um die Effekte von Forschung und Entwicklung $(\mathrm{FuE})$ in einer Region $\mathrm{zu}$ untersuchen. Auf Basis zweier negativer Binomialmodelle im Rahmen einer Wissensproduktionsfunktion wenden wir zudem den ,spatial filtering approach“ an, um für räumliche Autokorrelation zu kontrollieren. Diese kann auftreten, da die Innovationsfähigkeit in einem Kreis vermutlich auch von den angrenzenden Kreisen und deren FuE-Aktivitäten beeinflusst sein wird. Unsere Ergebnisse zeigen signifikant positive Effekte sowohl der öffentlichen als auch der privatwirtschaftlichen FuE auf die „Produktion“ von Nanomaterialpatenten. 


\title{
Knowledge Production in Nanomaterials: An Application of Spatial Filtering to Regional Systems of Innovation
}

\author{
Christoph Grimpe $\mathrm{a}^{\mathrm{a}, 1}$ and Roberto Patuelli ${ }^{\mathrm{b}}$ \\ ${ }^{\text {a }}$ ZEW - Centre for European Economic Research, Mannheim, Germany \\ Katholieke Universiteit Leuven, Belgium \\ University of Zurich, Switzerland \\ ${ }^{\mathrm{b}}$ Institute for Economic Research (IRE), University of Lugano, Switzerland \\ Rimini Centre for Economic Analysis, Rimini, Italy
}

\begin{abstract}
Nanomaterials are seen as a key technology for the 21st Century, and much is expected of them in terms of innovation and economic growth. They could open the way to many radically new applications, which would form the basis of innovative products. In this context, it seems all the more important for regions to put their own innovation systems in place, and to ensure that they offer a suitable location for such activities in order to benefit from the expected growth. Many regions have already done so by establishing 'science parks' and 'nanoclusters'. As nanomaterials are still in their infancy, both public research institutes and private businesses could play a vital role in the process. This paper investigates what conditions and configurations allow a regional innovation system to be competitive in a cutting-edge technology like nanomaterials. We analyse European Patent Office data at the German district level (NUTS-3) on applications for nanomaterial patents, in order to chart the effects of localised research and development (R\&D) in the public and private sector. We estimate two negative binomial models in a knowledge production function framework and include a spatial filtering approach to adjust for spatial effects. Our results indicate that there is a significant positive effect of both public and private $R \& D$ on the production of nanomaterial patents. Moreover, we find a positive interaction between them which hints at the importance of their co-location for realising the full potential of an emerging technology like nanomaterials.
\end{abstract}

Keywords: nanotechnology, innovation, patents, Germany, spatial autocorrelation, spatial filtering

JEL-Classification: L60, O32

Acknowledgements:

We thank Charlotta Mellander, Christian Rammer, Andrea Vaona and participants at the Eleventh Uddevalla Symposium 2008 in Kyoto for helpful insights and discussions.

1 Corresponding author; ZEW - Centre for European Economic Research, Department of Industrial Economics and International Management, P.O. Box 1034 43, D-68034 Mannheim, Germany, Phone: +49/621/1235-381, Fax: +49/621/1235-170, E-mail: grimpe@zew.de 


\section{$1 \quad$ Introduction}

Nanotechnology has been identified as one of the key technologies for the 21st Century. The application of nanotechnology is expected to result in new functionalities and properties for improving products or developing new products and applications (Meyer, 2006). Nanotechnology is therefore believed to contribute substantially to innovativeness, economic growth and employment (Bozeman et al., 2007). Although the nanometre by definition corresponds to one millionth millimetre $\left(10^{-9} \mathrm{~m}\right)$ there is, however, no common understanding about what nanotechnology actually comprises (Fleischer, 2002). A reason for this might be the wide array of potential applications, e.g. in biotechnology, optics, chemistry or material sciences. Nanotechnology is hence seen as exhibiting certain characteristics of a 'General Purpose Technology (GPT)' like the information and communication technology (Youtie et al., 2008). Due to this heterogeneity in applications we will focus in the following on the intersection of nanotechnology and material sciences, an area where most of today's applications of nanotechnology have been achieved, e.g. in the 'lotus effect' of surfaces. The corresponding term 'nanomaterials' refers to functional structures sized less than 100 nanometres (Youtie et al., 2008). Such structures give the material specific properties, allowing them to be used in new ways, to bring about new effects in larger structures of which they are part.

Given the perspective of many radically new applications, which could form the basis of innovative products, it seems all the more important for regions to put their own innovation systems in place, to ensure that they offer a suitable location for such work and are thus able to benefit from the growth that is expected to result from nanomaterial applications. Initially, innovation systems had been referred to nation states (Lundvall, 1992; Nelson, 1993; Edquist, 1997) but the concept has been extended to the regional level as well (Cooke et al., 1997, 2000; Howells, 1999). The fundamental idea behind the concept of regional systems of innovation is the notion that industries tend to concentrate in certain spaces. While being part of the national system of innovation, a regional system of innovation can be defined as a regional network between public and private science and the government to adapt, generate and extend knowledge and innovations (Howells, 2005; Buesa et al., 2006). Many regions have recognised the importance of promoting research activities in nanotechnology, which has led to the establishment of 'science parks' and 'nanoclusters' that are substantially supported by public policy. Moreover, as nanomaterials are still in their infancy and related products at an early phase of their life-cycles, cooperation between public research institutes and private businesses has a vital role to play to create the required knowledge for actually benefiting from nanomaterials research.

As it has become a part of conventional wisdom that most developed market economies are now based on knowledge, new economic theories have included knowledge more directly in production functions (Griliches, 1979). The reasoning behind this analysis is based on the idea that investments in knowledge, which may be embodied in people and technology, increase the productivity of capital and labour resulting in new products and processes. It will thus be 
of interest - particularly for policy makers at the regional level - to investigate which key factors influence research output at the aggregate level, and what can be done to foster knowledge creation in an emerging field of technology. The endogenous growth model developed by Romer (1990) states that knowledge production increases with research input, and in particular with input in terms of human capital. Hence, in this paper, we wish to analyse knowledge creation in nanomaterials as a specific economic activity using the knowledge production function (KPF) framework. The objective is to analyse the determinants of knowledge production by linking the observable innovative output - patents to observable inputs. We consider three types of inputs: private and public investments in research and development (R\&D) (both in terms of personnel), as well as the technological specialisation of a region.

Previous studies that have estimated KPFs using patent data are mainly based on aggregate country level statistics on patenting activity (e.g., Porter and Stern, 2000; Furman et al., 2002; Jaummotte and Pain, 2005; Luintel and Khan, 2005). Our objective is to focus on an emerging field of technology which is likely to exhibit considerably different determinants of patenting than the aggregate patent stock of an innovation system. A reason for this might be that the development of emerging technologies requires a close connection of the industry with universities and research institutes. We analyse European Patent Office (EPO) data on the German district (NUTS-3) level on applications for nanomaterial patents.

As we set off to analyse regional innovation systems, one aspect ought to be taken into consideration, that is, the correlation 'in space' among regions. Spatial autocorrelation (SAC) (Cliff and Ord 1981) can be defined as the correlation amongst the values of a georeferenced variable that is attributable to the proximity of the objects to which the values are attached. SAC may be due, among other reasons, to self-correlation, omitted/unobserved variables, redundant information, or spatial spillover effects. SAC is most evident, for example, in the case of Germany, in the still-existing East/West economic divide. Accounting for SAC is necessary in order to correctly assess the economic relations being studied since it makes standard statistics such as correlation coefficients potentially inappropriate. To account for $\mathrm{SAC}$, we introduce a spatial filter - within a negative binomial estimation - in a KPF framework, with a view to finding out whether innovative activities in the field of nanomaterials systematically depend on regional characteristics.

The remainder of the paper is organised as follows: The next chapter will focus on the role of regional systems of innovation in fostering the development of emerging technologies like nanomaterials. The third section presents our KPF model and discusses the issues of nonlinearity and spatial dependence when estimating the KPF. The fourth section shows the results of the empirical application to German nanomaterial patents. Section 5 closes with concluding remarks and avenues for further research. 


\section{Regional Systems of Innovation and Emerging Technologies}

It has been widely acknowledged that innovation and knowledge generation are a major determinant of economic development and the competitiveness of firms, regions and nations (Tödtling and Trippel, 2005). This is reflected in the policy agendas which have put the support for innovation activities at the top in industrial and regional policy. Adopting a rather abstract view, innovation policy is directly tied with national interests and hence with a more macro-oriented perspective (Howells, 2005). Nevertheless, the literature has also pointed to the importance of regional contexts affecting innovation and to the systemic nature of the innovation process (Feldman and Audretsch, 1999). While systems of innovation had initially been referred to nation states (Lundvall, 1992; Nelson, 1993; Edquist, 1997), the concept has consequently been extended to the regional level (Cooke et al., 1997, 2000; Howells, 1999). The key notion behind the concept of regional systems of innovation is that industries tend to concentrate in certain spaces. Although regional systems of innovation are still part of the national system of innovation, they can be defined as a regional network between various actors comprising public and private science and the government. Their interaction serves as a way to adapt, generate and extend knowledge and innovations (Howells, 2005; Buesa et al., 2006).

There are, however, two contradicting views on the link between public policy, innovation and regional economic performance. In a nation state characterised by heterogeneous eonomic conditions and factor endowments there will certainly be regions that lag behind in terms of innovative activity. Hence, supporting these regions by public policy to become more innovative would directly translate into growth and performance of the nation state (Howells, 2005). The alternative view states it is not an increase of national performance resulting from such policy initiatives but rather a decrease. The reason for this is that 'natural' development activities may not be touched without reducing economic efficiency. In this respect, efficiency refers to some kind of optimal pattern resulting from a given spatial distribution of resource and factor endowments as well as the transport possibilities (Martin, 1999; Howells, 2005).

Apart from this rather general remark on the opportunities and benefits of regional innovation policy, literature has pointed to the fact that such policy initiatives need to be differentiated according to the type of the regional innovation system. Tödtling and Trippl (2005), for example, distinguish peripheral regions from old industrial regions and fragmented metropolitan regions. Generally speaking, they find some indication of core-periphery differences of innovation. In this sense, $R \& D$, patenting and product innovation activities tend to be higher in larger agglomerations (Feldman and Audretsch, 1999). Such agglomerations also facilitate knowledge spillovers, i.e. the extent to which knowledge generated by one firm or region provides positive externalities to other firms or regions (Audretsch and Feldman, 1996). After all, complementarity effects between certain industries, e.g. between the pharmaceutical and biotechnology industry, need to be taken into account (Feldman and Audretsch, 1999).

It is less clear, however, how public policy should be differentiated according to the industry and, more specifically, to the underlying technology of an industry. Nanomaterials have been 
argued to show certain characteristics of a 'General Purpose Technology (GPT)' like the information and communication technology (Youtie et al., 2008). It is believed to contribute substantially to innovativeness, economic growth and employment (Bozeman et al., 2007). Nevertheless, nanomaterials come along with a high technological complexity, making it difficult for firms to access the economic potential of this technology. In fact, most applications of nanomaterials are still in their infancy. Many of them require the skills and expertise of technologically advanced universities and research institutes which have the ability to perform basic research activities. In this sense, we can argue that knowledge production in nanomaterials is different from other established technological fields. In these fields, new knowledge which is subsequently protected by patents mainly stems from applied research at industry-funded $R \& D$ units. In contrast to this, basic research, as it is necessary to advance the field of nanomaterials, is mostly performed at universities or government-funded research institutes which can actually 'afford' less application-oriented research.

The question remains whether nanomaterials then really are an issue that regional innovation systems should deal with. On the one hand, the argument here is that regional systems are far too small to deal with the complexity and dynamics of an emerging technology, as patenting and product innovation activities tend to be higher in larger agglomerations (Feldman and Audretsch, 1999). It might even be questionable if nanomaterials are a matter of national systems of innovation. As qualified nanomaterial research is globally dispersed, and with the availability of advanced information and communication technologies, collaborations between industry and science should presumably not be bound to geographical proximity in a particular region. On the other hand, the argument could be brought forward that nanomaterials can be an issue for regional systems of innovation when a region succeeds in attracting a 'critical mass' of nanomaterial competence. This case would argue for the existence of knowledge spillovers that become effective when research expertise is colocated, for example when joint research projects could be set up between firms and research institutes in a region (Audretsch and Feldman, 1996). The reason for this may be geographic boundaries to information flows, particularly because tacit knowledge is involved through the interaction of scientists (Krugman, 1991). As a consequence, proximity and location would matter, and we should be able to observe positive effects at the regional level. The central question is whether this argument also holds for the context of nanomaterials where complexity and dynamism might require to move beyond regional boundaries as the potential of knowledge spillovers may be too little to be useful in a regional context. Our first research question, therefore, centres around the effect of co-location of industry- and governmentfunded $R \& D$ on the knowledge production of regions in an emerging technology like nanomaterials. Moreover, it will be of interest what conditions and configurations allow a regional innovation system to be competitive in such a cutting-edge technology like nanomaterials. In this respect, our second research question analyses the characteristics of a region that are conducive for knowledge production in nanomaterials. As a result, these characteristics may serve as a starting point for regional policy makers aiming at an improvement of the regional conditions for the production of knowledge on nanomaterials. The following section will thus outline our model to test our theretical reasoning. 


\section{The model}

\subsection{Knowledge Production Function}

The concept of KPF can be regarded as a cornerstone of endogenous growth theory which points to public and private $\mathrm{R} \& \mathrm{D}$ as a key activity in achieving long-term productivity growth (Romer, 1990; Aghion and Howitt, 1992). The way to achieve this is by allocating resources to these activities. Therefore, if economic growth can in the long run be regarded as a function of the resources allocated to $R \& D$, then government policies that are designed to foster $R \& D$ investment may have a positive impact on sustainable economic growth (of the economy). In a simple specification, the KPF model comprises private and public investments in R\&D as generators of new knowledge. Moreover, the effect of these investments depends on the past stock of knowledge to which scientists may refer during the R\&D process. The stock of knowledge in turn creates a specific profile of technological specialisation which can be assumed to be conducive to a certain technology competence of a region, for example, as a 'centre of excellence' (Romer, 1990; Jones, 1995; Porter and Stern, 2000; Furman et al., 2002).

As in many empirical studies involving a KPF (e.g., Griliches, 1990; Patel and Pavitt, 1994), our measure of output is patents (see, for example, Acs et al., 2002, for a discussion of their role as measures of innovation). Without doubt, the use of patents as an indicator of technological innovation has some disadvantages (Griliches, 1990). First of all, not all inventions are patented as firms may choose other protection strategies like secrecy. Moreover, although a granted patent guarantees a certain level of originality and newness, research has shown that the value of patents is highly skewed, leading to a 'long tail' in the distribution (Harhoff et al., 2003), that is, only some patents are highly valuable. Regarding the relationship between input and output, it has to be considered that time lags exist between R\&D expenditure and patenting. Accordingly, our KPF is given by the following expression:

$$
\ln y_{i, t}=\alpha \ln x_{i, t-1}+\beta \ln z_{i, t-1}+\chi \ln a_{i, t-1}+\varepsilon,
$$

where: $y_{i, t}$ is the output of the knowledge production function in region $i$ and time $t, x_{i, t-1}$ is the research input; $z_{i, t-1}$ is the stock of knowledge of the region; $a_{i, t-1}$ includes other variables affecting innovation output; $\varepsilon$ is the error term assumed to be identically and independently distributed with a zero mean and constant variance; $\alpha, \beta$ and $\chi$ are the parameters to be estimated.

In addition to the above elements, the final model estimated in this paper includes - as an additional variable (or set of variables) - a so-called 'spatial filter'. The resulting model is then:

$$
\ln y_{i, t}=\alpha \ln x_{i, t-1}+\beta \ln z_{i, t-1}+\chi \ln a_{i, t-1}+s f_{i}+\varepsilon
$$


where $s f_{i}$ is the $i$ th element - corresponding to region $i$ - of the selected spatial filter. This is selected - on the basis of an earlier eigenvectors decomposition process - in a stepwise selection framework.

While Section 3.3 illustrates in a more detailed way how the spatial filter decomposition is computed, we first discuss, in the following section, the estimation issues tied to the nature of the data.

\subsection{Estimation of Count Data Regressions}

The model specified above aims to explain the dependent - the output of the KFP - in terms of a number of explanatory variables. In our model, output is measured as the number of patent applications in the field of nanomaterials submitted over a certain period in a given region. It is immediately clear that we are dealing with count data, that is, a variable that cannot assume values smaller than 0 , and that will have to be treated as an integer.

Given the nature of the data (non-negative and skewed), hypothesising a Gaussian-based underlying distribution as it is done for example in ordinary least squares estimations is misleading. Poisson regressions are commonly used for estimating models with count data as a dependent variable. In this case, a generalised linear model (GLM) can be adopted, using the logarithm - rather than the identity function - as a link function. However, a Poisson regression implies an equivalence between the conditional variance and the conditional mean. This is often not true in economics where an overabundance of zeros as well as under- or over-dispersion are frequent phenomena.

The latter problem is often taken into account by employing a negative binomial distribution. A discrete variable may follow this distribution as a result of a two-stage model including an unobserved gamma-distributed variable $E$ with mean 1 and variance $1 / \theta$, while the discrete variable at study is Poisson-distributed conditionally to $\mathrm{E}$ with mean $\mu$ and variance equal to $\mu$ $+\mu^{2} / \theta$ (Venables and Ripley, 2002). The dispersion parameter $\theta$ is iteratively fitted, and can be estimated according to different methods (by maximum likelihood or by means of $\theta$ 's moment estimator). An initial (first-iteration) estimate of $\theta$ can be obtained, for example, from a Poisson regression. As a consequence, the negative binomial estimation framework was chosen for our analysis, in particular because of overdispersion concerns. The next section discusses how spatial autocorrelation can be accounted for in such an estimation framework.

\subsection{Spatial Autocorrelation and Spatial Filtering}

As briefly hinted at in Section 1, a critical aspect when analysing data at the regional level is considering the role that 'space' plays in the knowledge production process. On the one hand, an established literature and the popular theories of the new economic geography (NEG) aim to explain and model spatial effects from an economic viewpoint through the definition, for instance, of spatial spillover effects, agglomeration and network externalities. On the other 
hand, spatial econometric techniques attempt to take into account the spatial effects that are left unexplained, which emerge as spatial autocorrelation (SAC) in the regression residuals.

While the economic aspects of the regional innovation systems studied here are included in the proposed KPF model (Equation (1)), additional econometric adjustments, in order to model the possible residual SAC, are desirable.

The most commonly used indicator of SAC is Moran's I (MI). The statistic is computed as follows:

$$
I=\frac{N \sum_{i} \sum_{j} w_{i, j}\left(x_{i}-\bar{x}\right)\left(x_{j}-\bar{x}\right)}{\left(\sum_{i} \sum_{j} w_{i, j}\right) \sum_{i}\left(x_{i}-\bar{x}\right)^{2}},
$$

where: $N$ is the number of cases; $x_{i}$ is the value of the variable $X$ in region $i$; and $w_{i, j}$ is the $(i, j)$ cell value of the geographic weights matrix $\mathbf{W}$ (defined below). Positive values of the MI imply that positive SAC; that is, similar values of the variable examined tend to be found for regions that are geographically close. On the other hand, negative MI values imply negative SAC, meaning a tendency to discordance between the values of close regions.

The above measure of SAC requires the use of a geographic weights matrix usually referred to as $\mathbf{W}$. This is an exogenously-defined $(N \times N)$ matrix which defines the relations of proximity between the regions - or within any other type of georeferenced data. Binary geographic weights matrices are often used for this aim. A value of 1 for the generic cell $(i, j)$ implies that the two regions $i$ and $j$ are neighbours while the opposite applies for the value 0 . Several standardisation schemes exist for the use of the $\mathbf{W}$ matrix, of which the most frequently employed is row-standardisation (for additional coding schemes, see Tiefelsdorf et al., 1999; Getis and Aldstadt, 2004).

The spatial econometric literature has proposed, in particular over the last two decades, a number of techniques, aimed at controlling for autocorrelation of both the dependent and the explanatory variables, as well as of the residuals (see, for example, the Cliff-Ord-type model, Anselin, 1988 or Griffith, 1988). While these techniques are widely used in many fields of analysis they are based among other restrictions on an assumption of normality (with the exception of spatial logit/tobit models). However, as seen in Section 3.2, count data are not properly analysed unless the characteristics of their distribution (discrete, non-negative, highly skewed) are explicitly considered in the econometric model.

As a solution to the above problem, we propose the use of eigenvector-based spatial filtering techniques (Griffith, 2000, 2003) in order to account for spatial structures due to unobserved/omitted variables. The advantage of employing a spatial filtering approach is that it does not require a normality assumption nor other estimation restrictions and that it can therefore be applied to regressions with any underlying distribution (for example, to logistic and Poisson regression). Moreover, while other spatial filtering techniques such as, for example, the one in Getis (1995), work directly on the data by computing spatial and nonspatial components the technique used here leaves the original data unchanged while 'adding' explanatory power by means of the spatial filter. 
Mathematically, the spatial filtering techniques employed here are related to the computational formula of the MI. The starting point for the computation of a spatial filter is the definition of a spatial weights matrix (for example, a binary contiguity matrix). The methodology uses eigenvector decomposition techniques, in order to extract orthogonal and uncorrelated numerical components from a given $(N \times N)$ geographic weights matrix (Tiefelsdorf and Boots 1995). In this regard, the proposed approach is reminiscent of principal components analysis (PCA): in fact, both methodologies generate orthogonal and uncorrelated new 'variables' that can be employed in a regression analysis framework. However, on the one hand the PCA components may be given a straightforward economic interpretation since the computed eigenvectors are used to construct linear combinations of the variables concerned. On the other hand, a spatial filter is a linear combination of (a subset of the) eigenvectors extracted from an exogenous spatial weights matrix. Consequently, they do not have a straightforward economic meaning, and represent the latent SAC (or redundant information due to spatial interdependencies) that can be related to the georeferenced variable being studied, according to the given geographic weights matrix. In other words, the single eigenvectors may represent specific spatial patterns tied to administrative or socio-economic factors.

Formally, the above-mentioned eigenvectors are computed from a modified geographic weights matrix:

$$
\left(\mathbf{I}-\mathbf{1 1}^{\mathrm{T}} / N\right) \mathbf{W}\left(\mathbf{I}-\mathbf{1 1}^{\mathrm{T}} / N\right)
$$

where: $\mathbf{W}$ is the given geographic weights matrix; $\mathbf{I}$ is an $(N \times N)$ identity matrix; and $\mathbf{1}$ is an $(N \times 1)$ vector containing only 1's. Because of the transformation carried out (see Griffith, 2003), the sequence in which the eigenvectors of the modified matrix in Equation (4) are extracted so as to maximise the sequential residual MI values. Consequently, the first extracted eigenvector, E1, is the one which shows the greatest MI value among all subsequent eigenvectors. Accordingly, the second extracted eigenvector, E2, is the one which shows the greatest MI value while being uncorrelated to E1. The process continues with the final extraction of $N$ eigenvectors. The resulting set of vectors is the complete set of all possible (mutually) orthogonal and uncorrelated map patterns (Getis and Griffith, 2002). Notably, when visualised on a map, the first two extracted eigenvectors often identify major (smooth) geographical patterns along the cardinal points, that is, North-South and East-West (for example, the German East/West former divide). The subsequent eigenvectors tend to display map patterns at a gradually smaller scale (from global to regional to local patterns).

The above eigenvectors may be employed as additional regressors in an otherwise non-spatial regression framework. The advantage implied by the orthogonality of the eigenvectors is that no issues arise with respect to partial correlations and multicollinearity. Additionally, (a subset of) the eigenvectors may function as proxies for missing explanatory variables. From a spatial dependence point of view the eigenvectors account for the residual SAC in the data, therefore 'cleaning' the regression residuals. Actually, each eigenvector used as a regressor is considered to be part of the final 'spatial filter' for the dependent variable. 
However, it is clear that employing all $N$ eigenvectors in a regression framework is not desirable for reasons of model parsimony. Further, in a cross-sectional framework, the number of explanatory variables would be equal to or greater than the number of observations. A smaller set of so-called 'candidate' eigenvectors should then be selected from the full set of eigenvectors. This can be done on the basis of their MI values; that is, by selecting the most relevant spatial patterns. An MI threshold value can be used in this regard (see, for example, Section 4.2). Once a set of $M(<N)$ candidate eigenvectors has been defined a further selection may be carried out in order to relate the exogenous spatial patterns identified by the eigenvectors to the data at hand. Since the eigenvectors are orthogonal and uncorrelated this second selection of eigenvectors can be carried out in a stepwise regression framework. The resulting subset of selected eigenvectors is what we will call the 'spatial filter' for the variable analysed. On the other hand, the final residuals of the stepwise regression are the spatially filtered component of the variable examined.

On the basis of the methodology presented above, the next section describes the empirical application carried out for our analysis of nanomaterial patents.

\section{$4 \quad$ The Empirical Application to German Nanomaterial Patents}

\subsection{Data}

As our knowledge production function framework suggests, we regress the number of nanomaterial patents on private and public investments in $R \& D$, on the stock of technology as well as on control variables and the spatial filter. Regarding the control variables, we focus on the size, the structure of the economy, and geographic/urban characteristics of a region, that is typology, urbanisation level, and agglomeration. Most challenges in data collection arise from the correct identification of nanomaterial patents. Given the diversity in opinion about how to define nanotechnology, a variety of search strategies has been developed by bibliometricians and patent analysts to capture the field (for a detailed discussion see Zitt and Bassecoulard, 2006; Schummer, 2004; Hullmann and Meyer, 2003). As a reliable identifying tag for nanotechnology patents has not yet become available at patent offices, ${ }^{2}$ this study has adopted a search strategy that evolved from a collaboration with a major European chemicals company which is one of the largest patent applicants in nanomaterials. We focus our analysis on patents applications at the European Patent Office (EPO) as these patents can, in contrast to

\footnotetext{
2 Nevertheless, the EPO has begun introducing such an identifier as an additional patent class (Y01N) which aims to provide information on developments in emerging technology fields. Consistency checks shows, however, that many nanomaterial patents have not yet been marked with this tag, particularly less recent patent documents.
} 
patent applications at national patent offices, be regarded as higher quality patents because the application costs are higher, so discouraging poor quality patent applications. ${ }^{3}$

The search strategy focused broadly on the field of nanomaterials. Searches were carried out in the databases 'Derwent World Patent Index', EPFULL, PCTFULL and PATDPAFULL. The 'Derwent World Patent Index' is a database which comprises the abstracts for patent documents from 41 countries, where the full abstract text was screened. With regard to the other three databases, which contain full patent documents, the search concentrated on the title, on the abstract, as well as on the claims. A substantial number of keywords in the field of nanomaterials were used. Moreover, the search comprised patents with a size indication of less than 100 nanometres (Youtie et al., 2008).

Talking about patents necessarily involves a discussion about the differentiation between patent applicant and patent inventor. While the applicant is the holder of the patent right, the document itself also shows the name(s) of the inventor(s). Typically, a firm would be the applicant of a patent invented by the firm's R\&D employees. In the German patent system, patents prepared within the employee's labour contract belong to the firm which in turn has to compensate the inventor according to the economic value of the patent. The differentiation between the applicant and the inventor is relevant in a spatial sense: While the applicant is typically located at one place, the inventors may be geographically dispersed around the applicant's location. Most larger firms, however, maintain several R\&D units while all patents are applied for from the firm's headquarter. This situation also applies to the large German science organisations like the Fraunhofer Society or the Max Planck Society. Both organisations are headquartered in Munich while the individual member institutes are scattered around Germany. Focusing on the patent applicant would hence lead towards a biased estimation of the innovative capacity of a particular region. We therefore revert to the inventor's location as a reference for the assignment of nanomaterial patents. Moreover, as patents may have been invented by several inventors located in different regions, we apply a fractional counting approach to assign every region mentioned the respective share of the nanomaterial patent.

Focusing on our explanatory variables, we measure the $R \& D$ inputs by means of the number of employees in private and public R\&D. The headcount is entered in relative terms into our estimation: private (public) $R \& D$ is defined as industry-funded (government-funded) $R \& D$ employees as a share of the total workforce. Moreover, in order to measure the importance of their joint location in a region, we include an interaction term of private and public R\&D in our second model specification (see Table 2). The technology stock of a region is identified by analysing patent applications (again referenced on the inventor's location) in the fields of mechanics, electronics, chemicals and pharmaceuticals. Patent applications in other technological fields are left out of the estimation as a reference group. Again, shares are calculated on the total number of patents produced in a region. The technology stock hence represents the technological specialisation of a region. As nanomaterials have been

3 We date the nanomaterial patents according to their application date as opposed to the granting date which conforms to common practice (e.g. Griliches, 1981). The application date has the advantage of being closer to the actual completion of the invention. 
characterised as exhbiting a cross-cutting nature, our specialisation patterns can also be assumed to reflect the stock of technological knowledge available for the scientists. Moreover, we include as control variables the economic structure and size of the regions to eliminate sheer size effects. For this purpose, we include the shares of employees employed in the manufacturing and services sector, the GDP per capita both in logs and as a squared term in logs, as well as the population in logs. Finally, we add three dummy variables, which describe the characteristics of the regions. The first dummy variable identifies the 'central cities', a formal classification of the 'core' areas of the main German cities; The second dummy variable identifies highly urbanised regions. Finally, the third dummy variable shows which regions belong to agglomerated areas. The three dummies were computed by authors on the basis of a composite index developed by Böltgen and Irmen (1997). ${ }^{4}$ With the exception of the technology stock, which has been identified using data from the EPO, the remaining explanatory variables are taken from the German federal statistical office (Destatis) and from the European statistical office (Eurostat) based on the German district (kreise) level (NUTS-3). Our measures account for time lags in the knowledge production function by using the sum of nanomaterial patents applied for in the years from 2000 to 2004 while all explanatory variables are based on the year 2000 .

At the spatial level, we may inspect the geographical distribution of the dependent variable, as well as the level of spatial autocorrelation (SAC) inherent to the data. Figure 1 provides a graphical visualisation of the number of nanomaterial patents in each German district. From the visual inspection of the map, it is clear that the geographical distribution of the patent applications cannot be considered random. A prevalence of high values for the Western regions of Germany can be highlighted. Most patents appear to be located - reasonably - in the major German cities and in specialised districts. ${ }^{5}$ Inversely, the East German kreise are identifiable - with few exceptions, such as Dresden, Halle and Berlin - with low patenting activities. Looking at SAC, the resulting value of the Moran's I for the dependent is equal to 0.28 , which denotes positive and significant SAC. The main argument why we observe SAC should be the existence of knowledge spillovers between the regions (see, for example, Anselin et al., 1997). Besides, SAC could occur if nanomaterial patents are developed in firms or universities and research institutes in a particular region while the inventors live either in that region or closely in neighbouring regions and commute to their work. Both aspects should lead to a rather high correlation between the individual regions.

4 Correlation between the three dummy variables is rather low, that is, below 0.4 .

5 An area of particular interest should be the one of Mannheim/Ludwigshafen in south-west Germany, where BASF, the largest chemicals company in Europe and a multiple nanomaterial patentee, is located. Another area of interest is the Ruhr area in the west of Germany. 
Figure 1: Geographic distribution of applications for nanomaterial patent applications by inventor

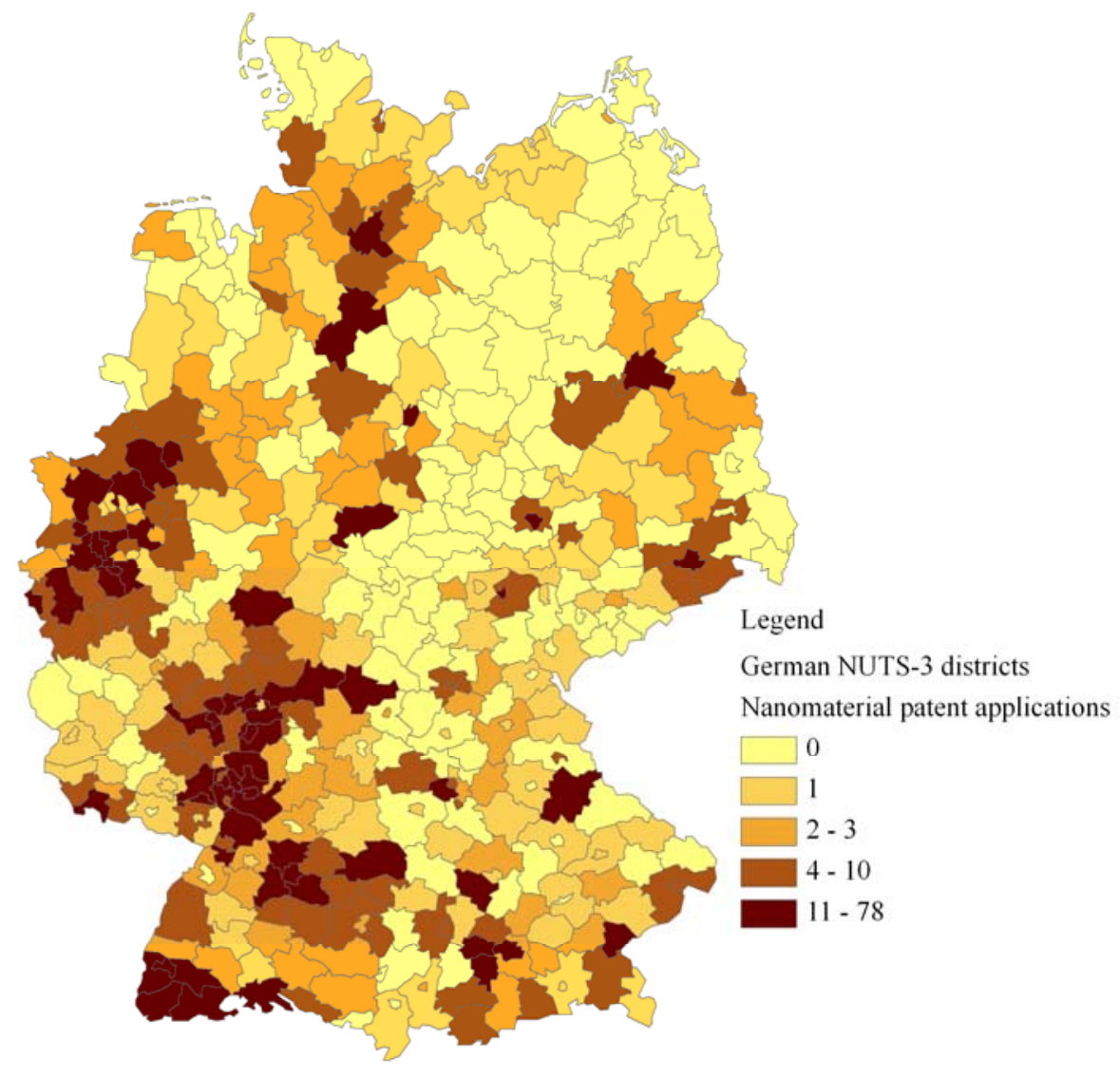

This level of spatial dependence will have to be adequately captured (explained) by our controls and explanatory variables, ideally resulting in spatially uncorrelated regression residuals. If this objective cannot be achieved by a non-spatial regression, then spatial econometric adjustments are necessary. The next section presents and briefly discusses the findings obtained for the spatial regressions.

\subsection{Results}

In total, 2161 nanomaterial patents were identified. Focussing on the patent applicant, most patents turn out to be applied for by companies ( 81.3 per cent) while universities and research institutes account for 11.1 per cent of the total. The remainder refers to patent applications by individuals or government agencies. Table 1 shows the descriptive statistics of our model variables. It turns out that on average almost five nanomaterial patents have been applied for in German regions from 2000 to 2004, with a minimum of 0 and a maximum of 78 patent applications in a region. 
Table 1: Descriptive statistics

\begin{tabular}{|c|c|c|c|c|c|}
\hline Variable & Obs. & Mean & Std. Dev. & Min & Max \\
\hline \multicolumn{6}{|l|}{ Dependent variable } \\
\hline Nanomaterial inventor patents & 439 & 4.866 & 9.490 & 0.000 & 78.000 \\
\hline \multicolumn{6}{|l|}{ Human capital inputs } \\
\hline Share of industry-funded R\&D employees (\%) & 439 & 0.008 & 0.011 & 0.000 & 0.080 \\
\hline Share of government-funded R\&D employees $(\%)$ & 439 & 0.004 & 0.009 & 0.000 & 0.096 \\
\hline \multicolumn{6}{|l|}{ Regional specialisation } \\
\hline Share of mechanics patents $(\%)$ & 439 & 0.436 & 0.163 & 0.039 & 1.000 \\
\hline Share of electronics patents $(\%)$ & 439 & 0.245 & 0.144 & 0.000 & 0.792 \\
\hline Share of chemicals patents $(\%)$ & 439 & 0.149 & 0.137 & 0.000 & 0.708 \\
\hline Share of pharmaceuticals patents (\%) & 439 & 0.064 & 0.067 & 0.000 & 0.420 \\
\hline \multicolumn{6}{|l|}{ Controls } \\
\hline Share of employees in manufacturing $(\%)$ & 439 & 27.558 & 11.338 & 3.881 & 65.530 \\
\hline Share of employees in services $(\%)$ & 439 & 8.073 & 3.705 & 2.277 & 21.475 \\
\hline GDP p.c. (in thousands of Euros) & 439 & 23.167 & 9.515 & 11.255 & 77.940 \\
\hline Population (thousands) & 439 & 127.363 & 153.474 & 23.509 & $2,439.539$ \\
\hline
\end{tabular}

Figure 2 shows a histogram of the nanomaterial patents for the 439 German districts. There are only a few regions that exhibit a very high number of patents while the vast majority of regions possesses no patents at all or only a few. The figure suggests that the distribution of patents is highly skewed.

\section{Figure 2: Histogram of nanomaterial inventor patents}

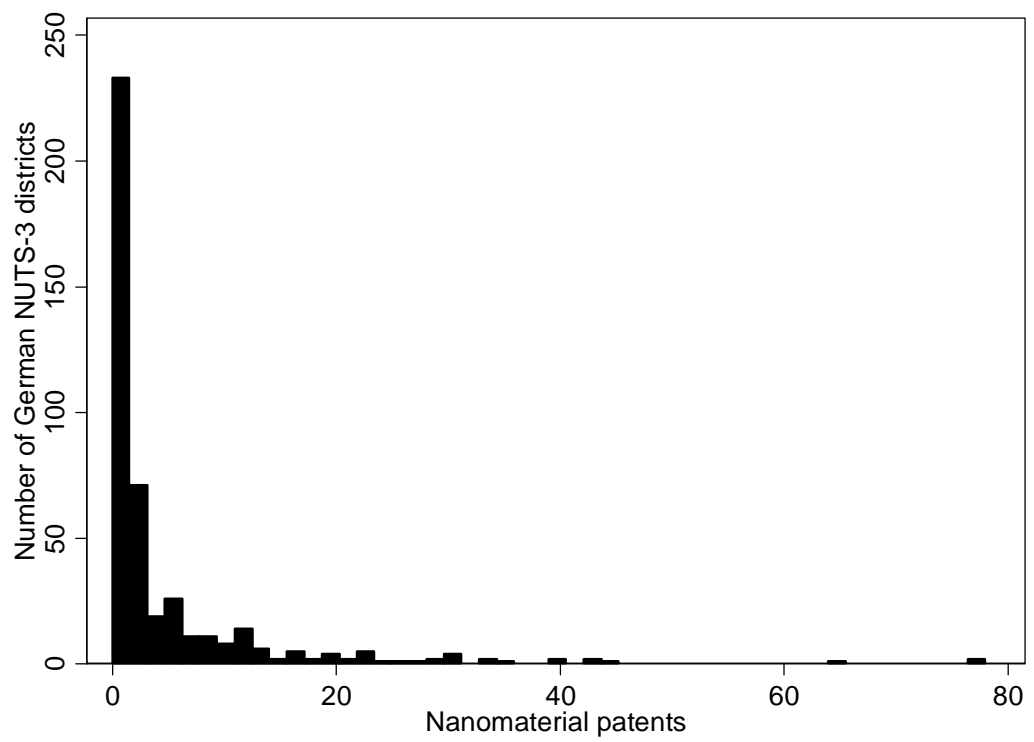

Regarding the explanatory variables it turns out that there are considerably more industryfunded R\&D employees than government-funded scientists. Moreover, most regions are specialised on mechanics, followed by electronics and chemicals. In terms of employment, the regions are on average more focused on manufacturing than services. The average GPD per capita equals roughly $€ 23,000$ with substantial regional disparities. These disparities also emerge in terms of population with an average of around 127,000 individuals per region. Our three dummy variables identify 72 central cities, 287 highly-urbanised regions, and 147 regions (mostly in West Germany) in agglomerated areas, respectively. 
As hinted at in Section 4.1, a non-spatial model could be considered appropriate - in addition to its explanatory power from an economic theory viewpoint - if it were able to properly account for spatial dependence. Therefore, we may look at the value of the MI statistic computed on the residuals, which, for the simple non-spatial negative binomial estimations is equal to 0.19 and 0.20 , for Model 1 and Model 2 (Table 2), respectively.. This MI value clearly shows positive and significant SAC that is not accounted for by our non-spatial models.

In order to adjust for SAC, we propose the use of spatial filtering-enhanced models, as described as Section 3.3. We start by defining a spatial weights matrix $\mathbf{W}$ of dimension $439 \times 439$, that is, a square matrix with as many rows and columns as the German kreise. Following a rook contiguity rule, for each pair $(i, j)$ of districts, the corresponding cell $(i, j)$ in $\mathbf{W}$ assumes value 1 if the two districts share a border, while it takes on value 0 if they do not share a border. The matrix is then rescaled, so as to sum 1 over all values (C-coding, see Chun et al., 2005; Tiefelsdorf and Griffith, 2007). After transforming W as in Equation (4), we then extract the related 439 orthogonal and uncorrelated eigenvectors, as well as the corresponding eigenvalues. Because of the matrix transformation applied, all the eigenvectors have the property of maximising SAC, while being orthogonal to the previously extracted eigenvectors. Consequently, the first eigenvectors show smooth surface partitions, resembling North-South and East-West patterns. A visualisation of the geographical distribution of the first two eigenvectors extracted for the spatial weight matrix $\mathbf{W}$ utilised in our study is given in Figure 4 in the Appendix.

We select a subset of eigenvectors - which we will refer to as 'candidate eigenvectors' according to the following threshold: $\operatorname{MI}\left(e_{i}\right) / \max _{i}\left[\operatorname{MI}\left(e_{i}\right)\right]>0.25$, where $\operatorname{MI}\left(e_{i}\right)$ is the $\mathrm{MI}$ computed on a generic eigenvector $i$. This threshold level roughly corresponds to a 95 per cent of variance explained in a regression of a generic $\mathbf{Y}$ on WY. The result of the selection process is a subset of 98 candidate eigenvectors to be used for estimation purposes. The candidate eigenvectors are added, as explanatory variables, to the non-spatial models (Equation 1), and evaluated in a stepwise regression framework. A stepwise negative binomial is used, for consistency with the estimation of the non-spatial model. The economic variables are set up as a minimum model, which cannot be discarded, while the single eigenvectors are added or thrown out on the basis of their contribution to the model fitness, as measured by the Akaike information criterion (AIC) (Akaike, 1974). Because AIC-based stepwise tends to overfit, a final backward selection is made manually, as additional eigenvectors are dropped on the basis of $\chi^{2}$ tests and according to a 95 per cent significance level.

The final result of the selection process is a set of 38 and 33 eigenvectors, for Model 1 and Model 2, respectively, all statistically significant (95 per cent at least). The spatial filtering specification appears to serve its purpose, since the MI values (reported in Table 2) for the spatial model's residuals are much lower $(-0.071$ and -0.045$)$ and even insignificant in the case of Model 2. The spatial filters computed have taken up the unexplained spatial dependence, as it is examplified in Figure 3, for the case of Model 2, by a visual comparison with the geographical distribution of nanomaterials patents (the dependent variable). 
Table 2: Results of the negative binomial models

\begin{tabular}{|c|c|c|c|c|}
\hline & \multicolumn{2}{|c|}{ Model 1} & \multicolumn{2}{|c|}{ Model 2} \\
\hline & Coefficient & Std. error & Coefficient & Std. error \\
\hline \multicolumn{5}{|l|}{ Human capital inputs } \\
\hline Share of industry-funded R\&D employees & 10.895 & $4.117^{* * *}$ & 6.029 & 4.919 \\
\hline Share of government-funded R\&D employees & 9.719 & $4.338^{* *}$ & 6.627 & 5.004 \\
\hline Interaction (industry- * government-funded R\&D) & & & 761.333 & $358.454^{* *}$ \\
\hline \multicolumn{5}{|l|}{ Regional specialisation } \\
\hline Share of mechanics patents & -0.894 & 0.950 & -0.546 & 0.957 \\
\hline Share of electronics patents & 2.024 & $0.882^{* *}$ & 2.341 & $0.900^{* * *}$ \\
\hline Share of chemicals patents & 3.402 & $0.964^{* * *}$ & 3.767 & $0.977^{* * *}$ \\
\hline Share of pharmaceuticals patents & 1.396 & 1.137 & 2.209 & $1.152^{*}$ \\
\hline \multicolumn{5}{|l|}{ Controls } \\
\hline Share of employees in manufacturing & 0.003 & 0.007 & 0.007 & 0.007 \\
\hline Share of employees in services & 0.072 & $0.022^{* * *}$ & 0.064 & $0.022^{* * *}$ \\
\hline GDP p.c. (in logs) & -0.769 & 5.679 & -0.444 & 5.764 \\
\hline GDP p.c. $(\text { in } \operatorname{logs})^{2}$ & 0.045 & 0.277 & 0.025 & 0.282 \\
\hline Population (in logs) & 0.196 & $0.050^{* * *}$ & 0.196 & $0.050^{* * *}$ \\
\hline Central city dummy & -0.351 & $0.155^{* *}$ & -0.329 & $0.158^{* *}$ \\
\hline Urbanisation dummy & 0.484 & $0.133^{* * *}$ & 0.456 & $0.134^{* * *}$ \\
\hline Agglomeration dummy & 0.355 & $0.124^{* * *}$ & 0.403 & $0.124^{* * *}$ \\
\hline Spatial filter & 1.000 & $0.060^{* * *}$ & 1.000 & $0.063^{* * *}$ \\
\hline Intercept & -0.492 & 29.033 & -2.028 & 29.486 \\
\hline$\Theta$ & 3.383 & - & 3.118 & - \\
\hline Null deviance (dof) & 1812.00 & $(438)$ & 1783.01 & $(438)$ \\
\hline Residual deviance (dof) & 422.09 & $(386)$ & 424.79 & $(390)$ \\
\hline AIC & 1747.80 & - & 1755.80 & - \\
\hline Pseudo $R^{2}$ & 0.719 & - & 0.645 & - \\
\hline Pseudo adjusted- $R^{2}$ & 0.681 & - & 0.601 & - \\
\hline MI (p-value) & -0.071 & $(0.022)$ & -0.045 & $(0.154)$ \\
\hline
\end{tabular}

Note: ${ }^{* * *},{ }^{* *},{ }^{*}$ indicate statistical significance at the $1 \%, 5 \%, 10 \%$ level, respectively.

Figure 3: Comparison between the geographical distributions of nanomaterial patent applications (left) and of the spatial filter computed for Model 2 (right)
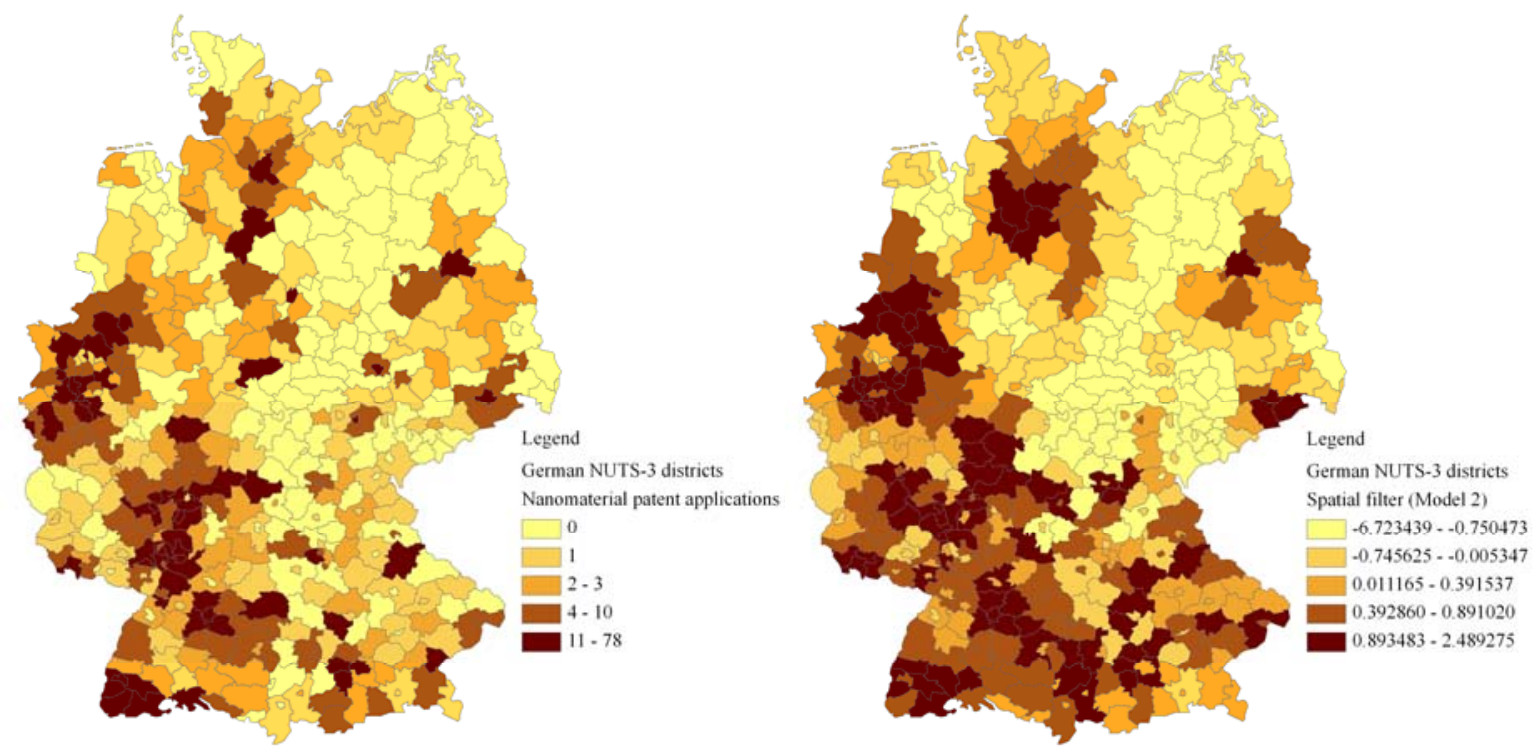
With regard to the human capital inputs our results in the first model specification (Model 1) indicate that both public and private $R \& D$ have a positive and significant effect on the creation of nanomaterial patents. This finding already hints at the importance of both sources of R\&D in an additive way. It does not yet show an effect 'on top' which is picked up in our second model specification (Model 2) by the interaction term. The interaction term shows a positive effect on knowledge production which underpins our reasoning of the benefits of colocation of public and private R\&D. Apparently, it is of great importance for a region whether opportunities for collaboration and knowledge spillovers arise. The result also provides an answer to our first research question, that is, whether an emerging technology like nanomaterials is really a topic that a regional innovation can deal with. It is not only the opportunity to collaborate with nanomaterial centres of excellence worldwide (which we cannot observe though), but the co-location of partners in innovation activities in a particular region that provides a major benefit.

Focusing on the regional specialisation there are highly significant and positive effects of a regional specialisation in electronics and chemicals across the two models. In fact, most nanomaterials are based on chemical strcutures or processes. But electronics seem to play an important role as well. Having established a stock of knowledge in these scientific fields hence creates an advantage for engaging in nanomaterial research. A specialisation in pharmaceuticals becomes weakly significant in Model 2 while mechanics patents seem not to be relevant.

With regard to the control variables, we can observe a positive and significant effect of a regional economic orientation towards the services industries. This hints at the importance of a rather modern economic orientation of a region. Furthermore, there is a positive and significant size effect indicated by the coefficient for population. These last findings make it clear that it is not only a sheer size effect that regional systems of innovation can succeed in nanomaterial research and knowledge production. Size matters but nanomaterial production seems to be dependent much more on human capital and on an adequate technological specialisation. Finally, the land use characteristics of the regions, as well as localisation, matter. The central city and urbanisation dummies show negative and positive signs, respectively, suggesting that factories and research facilities tend to be located in highly urbanised districts but less often in the nucleus of medium/large cities. The agglomeration dummy also presents a positive coefficient, suggesting that knowledge spillovers and economies of agglomeration play a role in the production of knowledge in nanomaterials. This finding is consistent with new economic geography and endogenous growth theories.

\section{$5 \quad$ Concluding Remarks}

In this paper, we have investigated the knowledge creation in nanomaterials as a specific economic activity using the knowledge production function (KPF) framework. Our objective was to analyse the determinants of knowledge production by linking the observable innovative output - patents - to observable inputs. We considered three types of inputs: 
private and public investments in research and development (R\&D) in terms of personnel as well as the technological specialisation of a region. Moreover, we were interested whether knowledge production in nanomaterials is in fact an issue that regional innovation systems could and should deal with. As nanomaterials exhibit a high technological complexity and dynamism, it might be questionable to what extent a region could actually benefit from a colocation of factors described in our knowledge production framework.

Our results indicate that nanomaterials are indeed an issue that regional policy makers can and therefore also should deal with. We find positive additive and interactive effects of public and private human capital as well as a favourable specialisation in electronics and chemistry. A region that deliberately wanted to benefit from the innovation and growth potentials of nanomaterials should hence particularly try to attract firms and research institutes doing research in electronics or chemistry. Moreover, supporting a close collaboration between the actors to facilitate knowledge spillovers should spur the production of nanomaterials. In this respect, the already existing 'nano clusters' or 'nano science parks' actually seem to be promising instruments for positioning the region as a hub for nanomaterial research. Our paper contributes to the literature on regional systems of innovation in that it focuses on nanomaterials as an emerging technology with high expectations for future economic growth. Although the complexity of nanomaterial research can be assumed to be substantial we are able to underline its regional dimension.

Future research should, in particular, try to generate empirical evidence on the long-term determining factors of knowledge production in nanomaterials. These factors might change with the maturity of the technology field. As first-mover advantages can be considered to be important in order to attract firms, research institutes as well as public funding, it would be particularly interesting to investigate the characteristics of a region that succeeds in realising such advantages when a promising new technology is still in its infancy. Another aspect is the relationship between public and private $R \& D$ which needs to be explored in more detail. In this context it would be particularly interesting to see how both types of R\&D can collaborate so that knowledge actually spills over from academia to industry and viceversa so that research productivity can increase. 


\section{References}

Acs, Z.J., Anselin, L. and Varga, A. (2002): 'Patents and Innovation Counts as Measures of Regional Production of New Knowledge', Research Policy, 31, 1069-1085.

Aghion, P., and Howitt, P. (1992): 'A Model of Growth through Creative Destruction', Econometrica, 60 (2), 323-51.

Akaike, H. (1974): 'A New Look at the Statistical Model Identification', IEEE Transactions on Automatic Control, 19 (6), 716-23.

Anselin, L. (1988): Spatial Econometrics: Methods and Models, Kluwer Academic Publishers, Dordrecht Boston.

Anselin, L., Varga, A. and Acs, Z. (1997): 'Local Geographic Spillovers between University Research and High Technology Innovations', Journal of Urban Economics, 42, 422-448.

Audretsch, D. and Feldman, M. (1996): 'R\&D Spillovers and the Geography of Innovation and Production', American Economic Review, 86, 630-640.

Bozeman, B., Laredo, P. and Mangematin, V. (2007): 'Understanding the Emergence and Deployment of "Nano" S\&T', Research Policy, 36, 807-12.

Böltgen, F. and Irmen, E. (1997): 'Neue siedlungsstrukturelle Regions- und Kreistypen', Mitteilungen und Informationen der BfLR H., 1, 4-5.

Buesa, M., Heijs, J., Martínez Pellitero, M. and Baumert, T. (2006): 'Regional Systems of Innovation and the Knowledge Production Function: The Spanish Case', Technovation, 26, 463-72.

Chun, Y., Bivand, R. and Tiefelsdorf, M. (2005): 'Using Open Source Data Analysis Environments for Prototyping Modelling Implementations for Spatial Data: Weights in R'. Paper presented at the Geo-Computational Meeting, Ann Arbor, MI, August 1-3.

Cliff, A.D. and Ord, J.K. (1981): Spatial Processes: Models \& Applications, Pion, London.

Cooke, P., Gómez Uranga, M. and Etxebarría, G. (1997): 'Regional Systems of Innovation: Institutional and Organizational Dimensions', Research Policy, 26, 474-91.

Cooke, P., Boekholt, P. and Tödtling, F. (2000): The Governance of Innovation in Europe, Pinter, London.

Edquist, C. (1997): Systems of Innovation: Technologies, Institutions and Organizations, Pinter, London.

Falk, M. (2005): 'What Determines Patents Per Capita in Oecd Countries?', Vienna: Austrian Institute of Economic Research (WIFO), 23.

Feldman, M. and Audretsch, D. (1999): 'Innovation in Cities: Science-based Diversity, Specialization and Localized Competition', European Economic Review, 43, 409-429.

Fleischer, T. (2002): 'Technikfolgenabschätzungen zur Nanotechnologie - Inhaltliche und konzeptionelle Überlegungen', Technikfolgenabschätzung - Theorie und Praxis, 11 (3-4), 112-24.

Furman, J., Porter, M. and Stern, S. (2002): 'The Determinants of National Innovative Capacity', Research Policy, 31 (6), 899-933.

Getis, A. (1995): 'Spatial Filtering in a Regression Framework: Examples Using Data on Urban Crime, Regional Inequality, and Government Expenditures'. In: L. Anselin and 
R.J.G.M. Florax (eds), New Directions in Spatial Econometrics, Springer, Heidelberg, pp. $172-85$.

Getis A. and Aldstadt, J. (2004): 'Constructing the Spatial Weights Matrix Using a Local Statistic', Geographical Analysis, 36 (2), 90-104.

Getis, A. and Griffith, D.A. (2002): 'Comparative Spatial Filtering in Regression Analysis', Geographical Analysis, 34 (2), 130-40.

Griliches, Z. (1979): 'Issues in Assessing the Contribution of Research and Development to Productivity Growth', Bell Journal of Economics, 10 (1), 92-116.

Griliches, Z. (1981): 'Market Value, R\&D and Patents', Economics Letters, 7, 183-187.

Griliches, Z. (1990): 'Patent Statistics as Economic Indicators: A Survey', Journal of Economic Literature, 28, 1661-703.

Griliches, Z. (1998): R\&D and Productivity, The University of Chicago Press, Chicago and London.

Griffith, D.A. (1988): Advanced Spatial Statistics, Kluwer Academic Publishers, Dordrecht.

Griffith, D.A. (2000): 'A Linear Regression Solution to the Spatial Autocorrelation Problem', Journal of Geographical Systems, 2, 141-56.

Griffith, D.A. (2003): Spatial Autocorrelation and Spatial Filtering: Gaining Understanding through Theory and Scientific Visualization, Springer, Berlin New York.

Harhoff, D., Scherer, F.M. and Vopel, K. (2003): 'Citations, Family Size, Opposition and the Value of Patent Rights', Research Policy, 32, 1343-63.

Howells, J. (1999), 'Regional systems of innovation?', in Archibugi, D., Howells, J., Michie, J. (Eds), Innovation Policy in a Global Economy, Cambridge University Press, Cambridge, 67-93.

Howells, J. (2005): 'Innovation and Regional Economic Development: A Matter of Perspective?', Research Policy, 34, 1220-34.

Hullmann, A. and Meyer, M. (2003): 'Publications and Patents in Nanotechnology. An Overview of Previous Studies and the State of the Art', Scientometrics, 58 (3), 507-27.

Jones, C. (1995): 'R\&D Based Models of Economic Growth', Journal of Political Economy, $103,739-84$.

Kortum, S. and Lerner, J. (2000), 'Assessing the Contribution of Venture Capital to Innovation', Rand Journal of Economics, 31, 674-92.

Krugman, P. (1991): Geography and Trade, MIT Press, Cambridge, MA.

Lundvall, B.A. (1992): National Systems of Innovation: Towards a Theory of Innovation and Interactive Learning, Pinter, London.

Martin, R. (1999): 'The New Geographical Turn in Economics: Some Critical Reflections', Cambridge Journal of Economics, 23, 65-91.

Meyer, M. (2006): 'Are Patenting Scientists the Better Scholars? An Exploratory Comparison of Inventor-authors with their Non-inventing Peers in Nano-science and Technology', Research Policy, 35, 1646-62.

Nelson, R.R. (ed.) (1993): National Innovation Systems: A Comparative Study, Oxford University Press, New York.

Nesta, L. and Patel, P. (2004): 'National Patterns of Technology Accumulation: Use of Patent Statistics'. In: H.F. Moed, W. Glanzel and U. Schmoch (eds), Handbook of Quantitative Science and Technology Research, Kluwer Academic Publishers, Amsterdam. 
Patel, P. and Pavitt, K. (1991): 'National Innovation Systems: Why Are They Important and How They Can Be Measured and Compared', Economics of Innovation and New Technology, 67, 77-93.

Porter, M. and Stern, S. (2000): 'Measuring the "Ideas" Production Function: Evidence From International Output', NBER Working Paper, 7891.

Romer, P. (1990): 'Endogenous Technical Change', Journal of Political Economy, 98 (5), S71-S102.

Schummer, J. (2004): 'Multidisciplinarity, Interdisciplinarity, and Patterns of Research Collaboration in Nanoscience and Nanotechnology', Scientometrics, 59, 425-65.

Tiefelsdorf, M. and Boots, B. (1995): 'The Exact Distribution of Moran's I', Environment and Planning A, 27, 985-99.

Tiefelsdorf, M. and Griffith, D.A. (2007): 'Semiparametric Filtering of Spatial Autocorrelation: The Eigenvector Approach', Environment and Planning A, 39 (5), 1193 221.

Tiefelsdorf, M., Griffith, D.A. and Boots, B.N. (1999): 'A Variance Stabilizing Coding Scheme for Spatial Link Matrices', Environment and Planning A, 31, 165-80.

Tödtling, F. and Trippl, M. (2005): 'One Size Fits All? Towards a Differentiated Regional Innovation Policy Approach', Research Policy, 34, 1203-1219.

Ulku, H. (2004): 'R\&D Innovation and Economic Growth: An Empirical Analysis', IMF Working Paper 04/185.

Venables, W.N. and Ripley, B.D. (2002): Modern Applied Statistics with S, Springer, New York.

Youtie, J., Iacopetta, M. and Graham, S. (2008): 'Assessing the Nature of Nanotechnology: Can We Uncover an Emerging General Purpose Technology?', Journal of Technology Transfer, 33, 315-29.

Zitt, M. and Bassecoulard, E. (2006): 'Delineating Complex Scientific Fields by a Hybrid Lexical-citation Method: An Application to Nanosciences', Information Processing and Management, 42 (6), 1513-31. 


\section{Appendix}

Figure 4: First two eigenvectors (E1, E2) extracted from the transformed spatial weights matrix $\mathrm{W}$
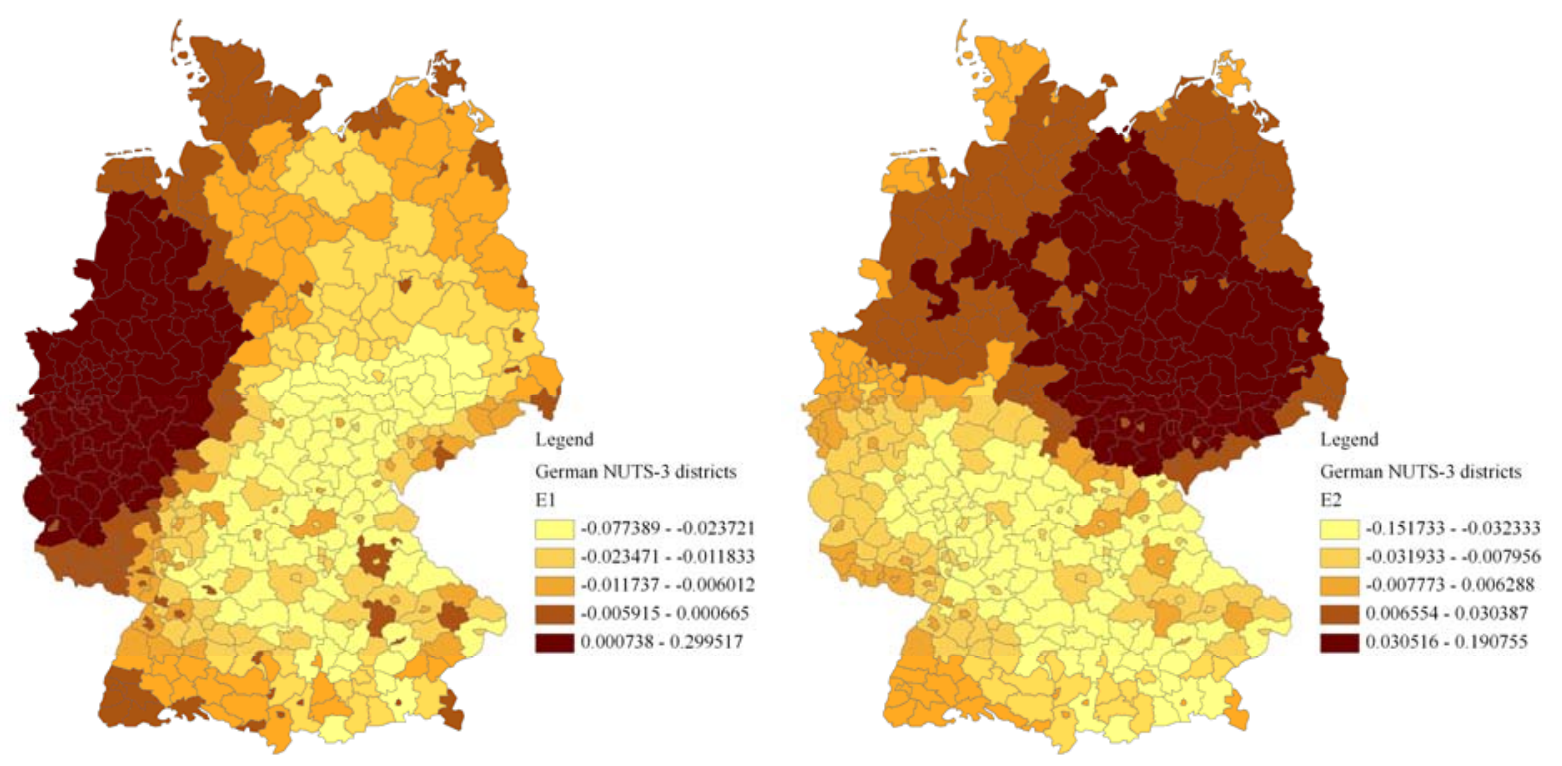